\title{
The Use of a Genetic Score in Assigning Students to Classes in PE Teacher Preparation Programs-A Preliminary Study
}

\author{
Sigal Ben-Zaken1, Ronnie Lidor'1, Alon Eliakim², Dan Nemet², Yoav Meckel' \\ ${ }^{1}$ The Academic College at Wingate, Wingate Institute, Netanya, Israel \\ ${ }^{2}$ Meir Medical Center, Child Health and Sports Center, Pediatric Department, and Sackler School of Medicine, \\ Tel-Aviv University, Tel Aviv, Israel \\ Email: sigalbz@wincol.ac.il
}

How to cite this paper: Ben-Zaken, S. Lidor, R., Eliakim, A., Nemet, D., \& Meckel, Y. (2018). The Use of a Genetic Score in Assigning Students to Classes in PE Teacher Preparation Programs-A Preliminary Study. Advances in Physical Education, 8, 172-182.

https://doi.org/10.4236/ape.2018.82016

Received: February 9, 2018

Accepted: May 12, 2018

Published: May 15, 2018

Copyright $\odot 2018$ by authors and Scientific Research Publishing Inc. This work is licensed under the Creative Commons Attribution International License (CC BY 4.0).

http://creativecommons.org/licenses/by/4.0/

\section{(c) (i) Open Access}

\begin{abstract}
A teacher preparation program for physical education (PE) is typically composed of a number of branches, including sport and exercise sciences, sport pedagogy, and activity classes. The activity classes play a key role in developing content knowledge that can be implemented by PE teachers in their classes. An attempt was made in this preliminary study to examine the use of a genetic score that has the potential to assist consultants/instructors in obtaining relevant information on the aerobic and anaerobic abilities of students enrolled in a PE teacher preparation program, as well as in assigning these students to activity classes included in the program. Participants were $219 \mathrm{PE}$ students (111 males and 108 females; mean age $=20-29$ yrs.), enrolled in a $\mathrm{PE}$ teacher preparation program at The Academic College at Wingate. Genomic DNA was extracted from peripheral blood samples. Genotyping of the $A C T N 3 \mathrm{R} / \mathrm{X}$ and $A C E \mathrm{I} / \mathrm{D}$ polymorphisms was performed using polymerase chain reaction (PCR). Two polygenetic scores were computed: Power Genetic Distance Score (PGDS2) and Endurance Genetic Distance Score (EGDS2). The main finding that emerged from our study was that both the male and female PE students were genetically predisposed toward aerobic skill rather than toward anaerobic skill: the students' mean EGDS2 $(52.6+23.0)$ was significantly higher compared to their mean PGDS2 $(36.3+21.9)(p<0.001)$. This finding can be applied by consultants who provide academic/educational advice to PE students for selecting activity classes in the PE program, as well as by the instructors who teach these classes. However, when applying this finding a number of ethical concerns should be taken into account.
\end{abstract}

\section{Keywords}

Physical Education, Genetic Score, Endurance Performance, Power 
Performance, Teacher Preparation Programs

\section{Introduction}

Physical education (PE) is considered to be a core subject in a typical school curriculum -in elementary, middle-high, and high school (see Penney, 2006; Wuest \& Fisette, 2015). PE is a multi-faceted discipline composed of a number of learning activities - particularly physical, but also cognitive, moral, and social. In PE classes, children are involved in various physical activities, including ball-game activities (e.g., basketball, soccer, volleyball), individual sports (e.g., gymnastics, track and field), and recreational activities (e.g., biking, walking). In addition, children are provided with the basic information required to perform these activities, such as the mechanics and techniques of the learned motor skills and the rules and tactics of competitions and games. They are also exposed to relevant knowledge related to $\mathrm{PE}$, such as how to maintain an active life style and how to develop good nutritional habits.

In order to enable the effective preparation required for students who aim at becoming $\mathrm{PE}$ teachers in schools, $\mathrm{PE}$ teacher preparation programs should reflect the multi-faceted nature of this discipline. Therefore, a teacher preparation program for PE is typically composed of three main branches-sport and exercise science studies, sport pedagogy, and activity classes (see, for example, Dodds, 2006; Lidor, 2011; Wuest \& Fisette, 2015). The objective of the sport and exercise science studies is to provide the student with the basic evidence-based knowledge that exists in a number of major PE-related disciplines, such as anatomy, biomechanics, measurement and evaluation in PE and sport, motor learning, and nutrition. The aim of the sport pedagogy studies is to provide the student with relevant knowledge on the educational, instructional, and pedagogical issues that are essential for teaching PE in the school system. The activity classes that are included in the program aim to a) improve the student's individual skills, and b) provide the students with applied knowledge in sport pedagogy in order to improve their teaching ability.

The activity classes provided in the $\mathrm{PE}$ teacher preparation programs play a key role in developing content knowledge that can be implemented by the teacher in PE classes (see Tsangaridou, 2016). Practically speaking, in the activity classes students acquire the relevant knowledge on how to teach the various motor/sport skills that children are expected to learn in PE classes, and which they will also use in their sport/recreation out-of-class activities. The students are physically active in these classes and repeatedly perform the learned skills in order to reach a certain level of mastery, which will eventually enable them to demonstrate these skills when teaching children in school.

Since the activity classes included in PE teacher preparation programs vary in their content-ball-game activities, individual sports, and recreational activities, 
the activities also vary in their physiological characteristics and requirements. For example, in these classes students are involved in aerobic regimes (e.g., jogging/running and biking for a long distance), anaerobic regimes (e.g., sprinting in track and field), or both regimes (e.g., team sports such as basketball, soccer, and volleyball). In addition, the students themselves vary in their physiological characteristics, as well as in their own preferences in selecting a given activity class. Due to the various activity classes that students are required to take in their program, a match between the characteristics of the class (activity) and those of the students may indeed exist, but this is not always the case. Furthermore, students who exhibit skill in one ability (e.g., aerobic ability) apparently prefer to select/attend classes emphasizing their favorable ability, since they anticipate having better achievements in these classes rather than in classes demanding other, non-favorable physiological aptitudes (e.g., anaerobic ability).

One of the main objectives of an effective PE teacher preparation program is to enable the students to study in classes that will provide them with holistic knowledge on how to teach children in schools. Therefore, the physiological characteristics of the students might be of particular interest to academic consultants who advise students as to which classes they should select in the PE preparation program. One of the aims of these consultants is to maintain a balance in the PE teacher preparation curriculum between the preferences of students in selecting classes that fit their own physiological/physical characteristics and their choice of classes which are required for their knowledge development, but do not match their personal characteristics.

Physiological/physical characteristics are multifactorial traits influenced by both genetic and environmental factors, as well as by the interactions among them. Since most likely a large number of genes and genetic variants are involved in aerobic/power predisposition, with each making only a small contribution to an individual's proficiency, new approaches have been applied for studying the genetic basis of aerobic/power capabilities that attempt to identify the genetic profile or create a genetic score (see, for example, Ben-Zaken, Meckel, Nemet, \& Eliakim, 2013; Ruiz et al., 2009).

An attempt was made in this preliminary study to examine the use of a genetic score that has the potential to assist academic consultants a) in obtaining relevant information on the aerobic and anaerobic abilities of PE teacher preparation students, and b) in assigning them to activity classes included in a PE teacher preparation program. This score could be used by consultants in addition to the scores from laboratory and field tests examining the aerobic and anaerobic abilities of individuals (see Hoffman, 2014; Tanner \& Gore, 2013). It is well known that aerobic and anaerobic abilities are largely genetically determined (Bouchard, Dionne, Simoneau, \& Boulay, 1992). A simple genetic score model in which both the aerobic and anaerobic genetic scores were computed based on two main genetic polymorphisms ( $A C T N 3 \mathrm{C} / \mathrm{T}$ and $A C E I / \mathrm{D}$ ) has previously been examined (Ben-Zaken, Meckel, Lidor, Nemet, \& Eliakim, 2013; Ben-Zaken, Meckel, Nemet et al., 2013). These specific genetic polymorphisms 
were selected because they are two-faced polymorphisms, with one allele associated with endurance performance and the other with power performance.

Therefore, the purpose of the current preliminary study was to use a simple genetic score model to characterize the genetic aerobic and anaerobic profile of students who were enrolled in a PE teacher preparation program. Such a characterization may assist them in planning an effective and balanced program of activity classes, as well as in the assignment of students to these classes. We discuss the obtained data from three perspectives-genetic scores of the aerobic and anaerobic abilities of the participants, curriculum considerations, and ethical concerns.

\section{Method}

\subsection{Study Population and Design}

Two-hundred and nineteen undergraduate PE students (111 males and 108 females; mean age $=20-29 \mathrm{yrs}$ ), who were enrolled in The Academic College at Wingate, volunteered to participate in the study. All the students were in the middle of their first year (i.e., the freshman year) of the four-year PE teacher preparation program. The number of the volunteer students who participated in our study represents the number of students who typically start the PE program at the College in a cohort year.

All the participants were healthy individuals who were not engaged in any individual or team competitive sports. The study was approved by the Institutional Review Board of the Hillel Yaffe Medical Center, Hadera, Israel, according to the Declaration of Helsinki. A signed informed consent was obtained from all participants.

\subsection{Genotyping}

Genomic DNA was extracted from each participant's peripheral EDTA treated anti-coagulated blood using a standard protocol. Genotype analyses were performed, as described below, in the Genetics and Molecular Biology Laboratory at The Academic College at Wingate. To ensure proper internal control for each genotype analysis, we used positive and negative controls from different DNA aliquots that had been previously genotyped by the same method, according to recommendations for replicating genotype-phenotype association studies (see Chanock et al., 2007). For all polymorphisms we used the polymerase chain reaction (PCR), and the resulting restriction fragment length polymorphism (RFLP) analysis was scored by two experienced and independent investigators who were blinded to the subject data. The RFLP technique exploits differences in DNA sequences, by using enzymes that cut lengthy DNA strands into short pieces. Each restriction endonuclease targets different nucleotide sequences in a DNA strand, and therefore cuts at different sites. The RFLP is performed using a series of steps, and the purified DNA is digested using restriction endonucleases. The restriction fragments produced during DNA fragmentation are analyzed 
using gel electrophoresis. Information on the primers, PCR annealing temperature, restriction enzyme, and fragments obtained for each allele for all studied polymorphisms is presented in Table 1 .

\subsection{Genetic Scores}

We computed the combined influence of two polymorphisms following a model used elsewhere (Ruiz et al., 2009, 2010; Williams \& Folland, 2008). We first scored each genotype within each polymorphism. We arrived at an additive model (equaling 0,1 , or 2 ), based on the number of alleles associated with a higher potential for endurance or power-speed performance that was carried by each participant for each polymorphism. Therefore, we assigned a genotype score (GS) of 2, 1, or 0 to each individual genotype, theoretically associated with the highest, medium, or lowest potential for endurance or power-speed performance, respectively. The studied polymorphisms are listed in Table 2.

EGDS2 was calculated based on two power-related genetic polymorphisms ( $A C E \mathrm{I} / \mathrm{D}$ and $A C T N 3 \mathrm{C} / \mathrm{T}$; see Table 2). EGDS2 is the Euclidean distance from the perfect endurance genetic score for these polymorphisms. Therefore, EGDS2 $=\operatorname{SQRT}[(2-$ GSACTN3 C/T $) 2+(2-$ GSACE I/D $) 2]$. The EGDS2 was transformed into a 0-100 scale for easier interpretation, as follows: EGDS2 $=100-$ $(100 / 8) \times(\operatorname{SQRT}[(2-$ GSACTN3 C/T $) 2+(2-$ GSACE I/D)2] $)$, where 8 is the result of multiplying 2 (number of studied polymorphisms) by 4 , which is the score given to the "worst" genotype. An EGDS of 100 represents an "optimal" endurance genetic profile, that is, all GSs are 2. In contrast, an EGDS of 0 represents the "worst" possible profile for an endurance genetic profile, that is, all GSs are 0. In the same way, we computed the PGDS2 based on two power-related genetic polymorphisms ( $A C E \mathrm{I} / \mathrm{D}$ and $A C T N 3 \mathrm{C} / \mathrm{T}$; see Table 2).

\subsection{Statistical Analysis}

We used a paired student's t-test to compare EGDS2 and PGDS2. We also compared EGDS2 and PGDS2 between males and females. Data are shown as mean \pm STD. Statistical significance was set at $p$ value $<0.05$.

Table 1. Endurance and power genetic polymorphisms.

\begin{tabular}{|c|c|c|c|c|c|}
\hline $\begin{array}{c}\text { Gene } \\
\text { Polymorphism }\end{array}$ & Reference ID & Primers $5^{\prime} \rightarrow 3^{\prime}$ & $\begin{array}{l}\text { Annealing } \\
\text { Temperature }\end{array}$ & $\begin{array}{l}\text { Restriction } \\
\text { Enzyme }\end{array}$ & Obtained Fragment \\
\hline ACE I/D & rs5186 & $\begin{array}{l}\text { ACE1-CAT CCT TTC TCC CATTTC TC } \\
\text { ACE2-TGGGATTACAGGCGTGATAC } \\
\text { ACE3-ATTTCAGAGCTGGAATAAAA }\end{array}$ & $62^{\circ}$ & Taq I & $\begin{array}{l}\mathrm{D} \text { allele } \rightarrow 84 \mathrm{bp} \\
\text { I allele } \rightarrow 64 \mathrm{bp}\end{array}$ \\
\hline ACTN3 R/X & rs1815739 & $\begin{array}{l}\text { F-5'CGCCCTTCAACAACTGGCTGGA 3' } \\
\text { R-5'GGGTGATGTAGGGATTGGTGGAG 3' }\end{array}$ & $62^{\circ}$ & DdeI & $\begin{array}{l}\mathrm{R} \text { allele } \rightarrow 250,86 \mathrm{bp} \\
\mathrm{X} \text { allele } \rightarrow 108,97 \mathrm{bp}\end{array}$ \\
\hline
\end{tabular}

Note: For all polymorphisms, the general cycle of PCR consisted of denaturation at $94^{\circ} \mathrm{C}$ for 5 min, 35 cycles of denaturation at $94^{\circ} \mathrm{C}$ for 1 min, annealing at $50^{\circ} \mathrm{C}$ for $1 \mathrm{~min}$, extension at $72^{\circ} \mathrm{C}$ for $1 \mathrm{~min}$, and a final extension step of $10 \mathrm{~min}$ at $72^{\circ} \mathrm{C}$. All restriction enzymes were obtained from New England Biolabs (Beverly, MA, USA). 
Table 2. Studied polymorphisms and genetic score.

\begin{tabular}{ccccc}
\hline Symbol & Gene & Polymorphism & Genotype Score (2 = "optimal" genotype) \\
\hline & & & Endurance Score & Power Score \\
ACE & Angiotensin converting enzyme & I/D (rs1799752) & $0=\mathrm{DD}, 1=\mathrm{ID}, 2=\mathrm{II}$ & $0=\mathrm{II}, 1=\mathrm{ID}, 2=\mathrm{DD}$ \\
$\mathrm{ACTN3}$ & Alpha-actinin-3 & $\mathrm{R} / \mathrm{X}(\mathrm{rs} 1815739)$ & $0=\mathrm{RR}, 1=\mathrm{RX}, 2=\mathrm{XX}$ & $0=\mathrm{XX}, 1=\mathrm{RX}, 2=\mathrm{RR}$ \\
\hline
\end{tabular}

\section{Results}

The participants' genetic scores represent their potential toward endurance (EGDS2) and power (PGDS2) performances. EGDS2 and PGDS2 are given on 0 to 100 scale, in which the value of 0 represents the "lowest" score, and the value of 100 represents the "highest" score. The participants' EGDS2 and PGDS2 means are shown in Figure 1. The participants' mean EGDS2 $(52.6+23.0)$ was significantly higher compared to their mean PGDS2 $(36.3+21.9)(p<0.001)$. The relatively high EGDS2 and the relatively low PGDS2 represent a substantial genetic predisposition towards endurance performance. Both the EGDS2 and the PGDS2 found in the current study are similar to those reported in our previous study on healthy non-athletic participants (Ben-Zaken et al., 2013).

The males' EGDS2 and PGDS2 did not differ from the females' EGDS2 and PGDS2, as can be seen in Figure 2.

\section{Discussion}

Data are discussed from three main perspectives, as follows: a) the genetic scores of the aerobic and anaerobic abilities of PE teacher students, b) PE teacher preparation curriculum considerations, and c) ethical concerns.

\subsection{Genetic Scores of Aerobic and Anaerobic Abilities of PE Teacher Students}

The main finding that emerged from our study was that both the male and the female students in a PE teacher preparation course were genetically predisposed toward aerobic performance rather than toward anaerobic performance. We used a simple model to compute the genetic aerobic score-EGDS2, and the genetic anaerobic score-PGDS2. EGDS2 and PGDS2 consist of two polymorphisms ( $A C T N 3 \mathrm{C} / \mathrm{T}$ and $A C E \mathrm{I} / \mathrm{D}$ ). These are two-faced polymorphisms, with one allele associated with endurance performance and the other allele with power performance, as mentioned previously. Therefore, although these scores were based on only two polymorphisms, we consider the comparison between them to be very constructive.

The ACTN3 gene encodes the synthesis of $\alpha$-actinin-3 in skeletal-muscle fibers, a sarcomeric protein necessary for the production of powerful "explosive" muscle contractions. A premature stop codon polymorphism [Arg(R)577Ter(X)] in ACTN3 was first described by North and colleagues (North et al., 1999). The absence of the $\alpha$-actinin-3 XX genotype is believed to induce top-level athletic performance in "pure" power and sprint sport events (Yang et al., 2003). In 


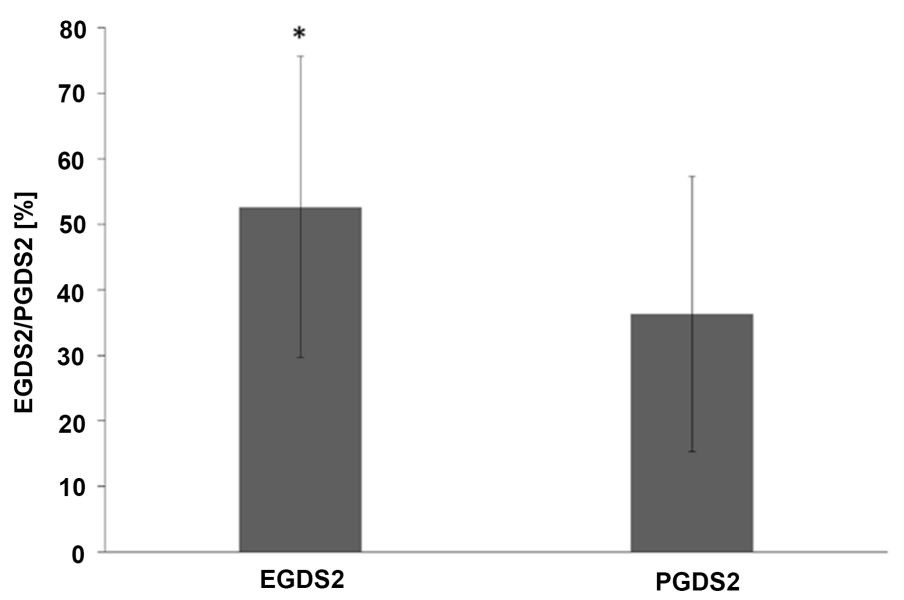

Figure 1. The endurance genetic distance score (EGDS2) and power genetic distance score (PGDS2) among students in a PE preparation program. Note: Each column represents the mean \pm SD. ${ }^{\star} p<0.001$.

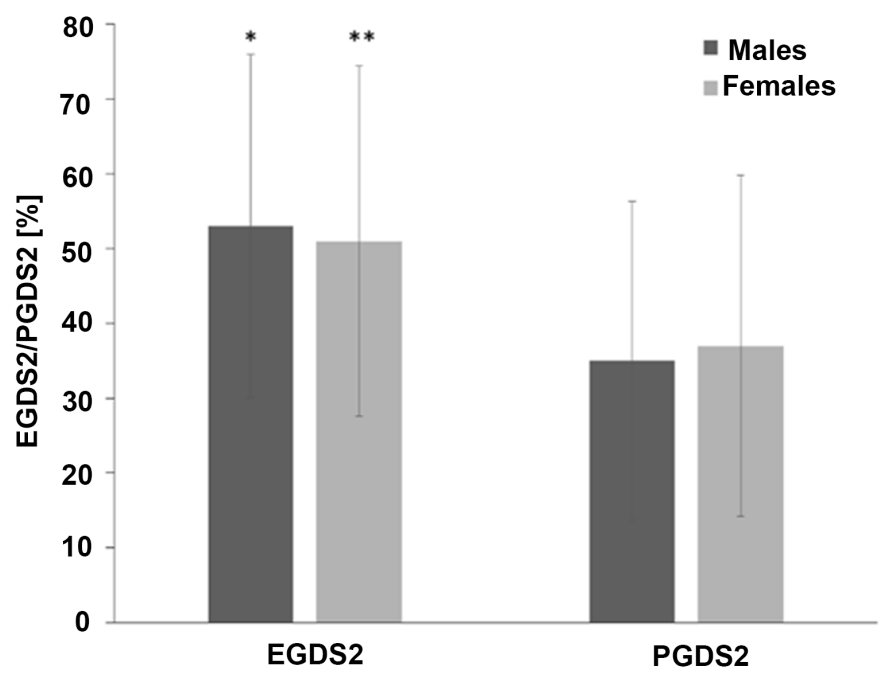

Figure 2. The endurance genetic distance score (EGDS2) and power genetic distance score (PGDS2) among students in a PE preparation program. Note: Each column represents the mean $\pm \mathrm{SD} .{ }^{\star} p<0.001$, ${ }^{* *} p<0.001$.

contrast, compared with the general population, the $\mathrm{X}$ allele tends to be overrepresented in elite endurance athletes (Lucia et al., 2006; Yang et al., 2003). A mechanistic explanation for the latter finding might be found in a-actinin-3 knockout (KO) mice. Compared with wild-type mice, the $\mathrm{KO}$ mice's muscles exhibited a shift towards increased mitochondrial oxidative metabolism, with 33\% higher endurance activity (MacArthur et al., 2007, 2008).

The $A C E \mathrm{I} / \mathrm{D}$ polymorphism has been studied extensively with regard to exercise-related phenotypes, and has been found to be related to cardiovascular and skeletal muscle function. An excess of the I allele has been associated with some aspects of low-intensity endurance performance (Sayed-Tabatabaei, Oostra, Isaacs, van Duijn, \& Witteman, 2006), probably due to the improvement of sub- 
strate delivery (Woods, Humphries, \& Montgomery, 2000) and skeletal muscle efficiency (Williams et al., 2000), and the subsequent conservation of energy stores (Montgomery et al., 1999). Conversely, an excess of the D allele has been reported among elite power-oriented athletes (Myerson et al., 1999) in a mechanism that is most likely mediated through differences in skeletal muscle strength gain (Folland et al., 2000).

\subsection{PE Teacher Preparation Curriculum Considerations}

The finding that PE students-females and males-are genetically predisposed towards aerobic skill rather than towards anaerobic (power/speed) skill, can be applied by consultants who provide academic/educational advice to students enrolled in PE teacher preparation programs. For example, consultants can recommend to students who have strong aerobic ability that they participate in activity classes where the focus is on anaerobic activities, and to those who are better in anaerobic activities that they take a number of aerobics classes. By participating in classes that do not match their own physiological characteristics, students can strengthen their entire arsenal of physical abilities, and better prepare themselves to teach these skills/activities in PE classes in schools.

In addition, if the majority of the students enrolled in a PE teacher preparation program are indeed genetically predisposed towards aerobic performance rather than towards anaerobic performance, then a policy of mixing the activities in the preparation program might be adopted. That is to say, a greater number of anaerobic classes, rather than aerobic classes, can be offered to these students. By this "re-mixture", the students can be provided with more task-enhancement learning opportunities aimed at strengthening their non-favorable (physical) abilities.

The use of a genetic score can also be considered as an additional assessment instrument for the aerobic and anaerobic abilities of PE teacher preparation students. Indeed, a variety of reliable and valid laboratory and field tests measuring aerobic and anaerobic abilities are already available to instructors and coaches in the motor domain (see, for example, Hoffman, 2014). However, administering the majority of these tests is time-consuming and requires unique apparatus and equipment. Furthermore, the outcomes of such tests are very often influenced to a great extent by a number of factors, among them emotional stress, technical and tactical skills, and environmental conditions. The use of a genetic score, even once, can be complemented by the results of the already-performed aerobic and anaerobic tests, and therefore can assist instructors/coaches to effectively measure and assess aerobic and anaerobic abilities.

\subsection{Ethical Concerns}

The potential use of genetic predisposition in young individuals (e.g., students in a PE teacher preparation program) may raise a number of ethical issues. For example, how do instructors and coaches who teach anaerobic-type activity classes in the PE teacher preparation program deal with students who lack the 
"appropriate" anaerobic genetic profile? Should these students be told that they don't have this "necessary" anaerobic genetic profile? If the answer to the second question is indeed positive, then how should this information be delivered to the students without hampering their motivation to achieve in their anaerobic classes?

Those who are involved in PE teacher preparation programs (e.g., academic consultants, policymakers) should be aware of these issues, and therefore develop an academic-educational policy that will account for the appropriate use of genetic profiles in higher-education programs, such as teacher preparation programs. In addition, to the best of our knowledge, the genetic scores of PE students have not been studied up to now. Therefore, additional research is required before a clear conclusion can be drawn with respect to the contribution of these scores in improving instructional processes in academic institutions. We assume that the identification of students from different disciplines (e.g., arts, life sciences, PE) by a genetic score has the potential to improve various instructional processes, such as the assignment of students to appropriate academic programs, and may influence their future occupation and career development.

\section{Conclusion}

The use of a genetic score has the potential to assist consultants and instructors in obtaining relevant information on the aerobic and anaerobic abilities of students enrolled in a PE teacher preparation program, as well as in assigning them to the activity classes included in the program. However, prior to the actual use of a genetic score in educational settings, two additional steps are required: a) to overcome a number of ethical challenges, and b) to obtain additional evidence-based information on the instructional processes associated with the calculated genetic score.

\section{References}

Ben-Zaken, S., Meckel, Y., Lidor, R., Nemet, D., \& Eliakim, A. (2013). Genetic Profiles and Prediction of the Success of Young Athletes' Transition from Middle- to Long-Distance Runs: An Exploratory Study. Pediatric Exercise Science, 25, 435-447. https://doi.org/10.1123/pes.25.3.435

Ben-Zaken, S., Meckel, Y., Nemet, D., \& Eliakim, A. (2013). Genetic Score of Power-Speed and Endurance Track and Field Athletes. Scandinavian Journal of Medicine \& Science in Sports, 25, 166-174.

Bouchard, C., Dionne, F. T., Simoneau, J. A., \& Boulay, M. R. (1992). Genetics of Aerobic and Anaerobic Performances. Exercise and Sport Sciences Reviews, 20, 27-58. http://www.ncbi.nlm.nih.gov/pubmed/1623888

Chanock, S. J., Manolio, T., Boehnke, M., Boerwinkle, E., Hunter, D. J., Thomas, G., \& Collins, F. S. (2007). Replicating Genotype-Phenotype Associations. Nature, 447, 655-660. https://doi.org/10.1038/447655a

Dodds, P. (2006). Physical Education Teacher Education (PE/TE) Policy. In D. Kirk, D. Macdonald, \& M. O’Sullivan (Eds.), The Handbook of Physical Education (pp. 540-561). Thousand Oaks, CA: Sage. 
Folland, J., Leach, B., Little, T., Hawker, K., Myerson, S., Montgomery, H., \& Jones, D. (2000). Angiotensin-Converting Enzyme Genotype Affects the Response of Human Skeletal Muscle to Functional Overload. Experimental Physiology, 85, 575-579. https://doi.org/10.1111/j.1469-445X.2000.02057.x

Hoffman, J. (2014). Physiological Aspects of Sport Training and Performance (2nd ed.). Champaign, IL: Human Kinetics.

Lidor, R. (2011). Physical Education Teacher Preparation Programs in Israel-Background, Structure, and Development. International Journal of Physical Education, 4, 31-38.

Lucia, A., Gómez-Gallego, F., Santiago, C., Bandrés, F., Earnest, C., Rabadán, M., \& Foster, C. (2006). ACTN3 Genotype in Professional Endurance Cyclists. International Journal of Sports Medicine, 27, 880-884. https://doi.org/10.1055/s-2006-923862

MacArthur, D. G., Seto, J. T., Chan, S., Quinlan, K. G. R., Raftery, J. M., Turner, N., \& North, K. N. (2008). An Actn3 Knockout Mouse Provides Mechanistic Insights into the Association between Alpha-Actinin-3 Deficiency and Human Athletic Performance. Human Molecular Genetics, 17, 1076-1086. https://doi.org/10.1093/hmg/ddm380

MacArthur, D. G., Seto, J. T., Raftery, J. M., Quinlan, K. G., Huttley, G. A., Hook, J. W., North, K. N. et al. (2007). Loss of ACTN3 Gene Function Alters Mouse Muscle Metabolism and Shows Evidence of Positive Selection in Humans. Nature Genetics, 39, 1261-1265. https://doi.org/10.1038/ng2122

Montgomery, H., Clarkson, P., Barnard, M., Bell, J., Brynes, A., Dollery, C., Humphries, S. et al. (1999). Angiotensin-Converting-Enzyme Gene Insertion/Deletion Polymorphism and Response to Physical Training. The Lancet, 353, 541-545.

Myerson, S., Hemingway, H., Budget, R., Martin, J., Humphries, S., \& Montgomery, H. (1999). Human Angiotensin I-Converting Enzyme Gene and Endurance Performance. Journal of Applied Physiology, 87, 1313-1316. http://www.ncbi.nlm.nih.gov/pubmed/10517757 https://doi.org/10.1152/jappl.1999.87.4.1313

North, K. N., Yang, N., Wattanasirichaigoon, D., Mills, M., Easteal, S., \& Beggs, A. H. (1999). A Common Nonsense Mutation Results in Alpha-Actinin-3 Deficiency in the General Population. Nature Genetics, 21, 353-354. https://doi.org/10.1038/7675

Penney, D. (2006). Curriculum Construction and Change. In D. Kirk, D. Macdonald, \& M. O'Sullivan (Eds.), The Handbook of Physical Education (pp. 565-579). London: Sage.

Ruiz, J. R., Arteta, D., Buxens, A., Artieda, M., Gómez-Gallego, F., Santiago, C., Lucia, A. et al. (2010). Can We Identify a Power-Oriented Polygenic Profile? Journal of Applied Physiology, 108, 561-566.

Ruiz, J. R., Gómez-Gallego, F., Santiago, C., González-Freire, M., Verde, Z., Foster, C., \& Lucia, A. (2009). Is There an Optimum Endurance Polygenic Profile? The Journal of Physiology, 587, 1527-1534.

Sayed-Tabatabaei, F. A., Oostra, B. A., Isaacs, A., van Duijn, C. M., \& Witteman, J. C. M. (2006). ACE Polymorphisms. Circulation Research, 98, 1123-1133. https://doi.org/10.1161/01.RES.0000223145.74217.e7

Tanner, R. K., \& Gore, C. J. (2013). Physiological Tests for Elite Athletes (2nd ed.). Champaign, IL: Human Kinetics.

Tsangaridou, N. (2016). Teachers' Knowledge. In D. Kirk, D. Macdonald, \& M. O'Sullivan (Eds.), The Handbook of Physical Education (pp. 502-515). London: Sage.

Williams, A. G., \& Folland, J. P. (2008). Similarity of Polygenic Profiles Limits the Potential for Elite Human Physical Performance. The Journal of Physiology, 586, 113-121. 
https://doi.org/10.1113/jphysiol.2007.141887

Williams, A. G., Rayson, M. P., Jubb, M., World, M., Woods, D. R., Hayward, M., Montgomery, H. E. et al. (2000). The ACE Gene and Muscle Performance. Nature, 403, 614-616.

Woods, D. R., Humphries, S. E., \& Montgomery, H. E. (2000). The ACE I/D Polymorphism and Human Physical Performance. Trends in Endocrinology and Metabolism: TEM, 11, 416-420. http://www.ncbi.nlm.nih.gov/pubmed/11091119 https://doi.org/10.1016/S1043-2760(00)00310-6

Wuest, D. A., \& Fisette, J. L. (2015). Foundations of Physical Education, Exercise Science, and Sport (18th ed.). New York, NY: McGraw Hill Education.

Yang, N., MacArthur, D. G., Gulbin, J. P., Hahn, A. G., Beggs, A. H., Easteal, S., \& North, K. (2003). ACTN3 Genotype Is Associated with Human Elite Athletic Performance. American Journal of Human Genetics, 73, 627-631. https://doi.org/10.1086/377590 